\section{Broader HIV Testing?}

The Centers for Disease Control (CDC) currently is working on draft guidelines aimed at providing broadened human immunodeficiency virus (HIV) testing services to inpatients and outpatients in acute-care hospital settings. Proposed recommendations include offering and encouraging HIV testing for all patients, especially those in high $(>1 \%)$ seroprevalence areas. In conjunction with the development of this draft, the CDC also has developed a "Guideline for Rapid Assessment of HIV Seroprevalence in Hospitalized Patients," which shows hospitals how to perform simple, rapid, and inexpensive seroprevalence surveys in an anonymous fashion. Such assessment surveys might help hospitals determine whether there is a need for more broad-based testing in their patient population. The rapid assessment guidelines are available free upon request by writing to Robert S. Janssen, MD, Population Study Section, Division of HIV/AIDS, Centers for Disease Control, 1600 Clifton Rd., Atlanta, GA 30333. Telephone (404) 6392082.

\section{Infection Control in the Office}

In response to concerns about infection control in the physicians office, representatives of the American Medical Society (AMA) met with representatives of SHEA and of the American Hospital Association (AHA) to discuss the need for educational activities, training, and possibly certification aimed at the office setting. The AMA will recommend that its board establish a task force to review these needs and propose a plan of action.

There are resources currently available for infection control education for dentists and personnel working in dental operatories through the American
Dental Association and the Dental Health Activity, National Center for Preventive Services, Centers for Disease Control. Washington State also is developing an infection control resource packet that will be made available for use in outpatient areas.

Anecdotal evidence suggests that of the many infection control issues in the office settingimproved handwashing, barrier precautions, reporting of communicable diseases, aseptic practices, and so on-reliable sterilization/ disinfection of instruments and devices probably should be the number one target of educational efforts.

\section{Fellowship in Hospital Epidemiology}

Two-year fellowship to begin July 1, 1992. Fellow will be trained in all aspects of infection control and hospital epidemiology including outbreak investigation, application of computers to hospital epidemiology, biostatistics, and hospital epidemiologic research.
Applicants should have an MD degree. Interested parties should contact C. Glen Mayhall, MD, University of Tennessee, Memphis, Division of Infectious Diseases, 956 Court Ave., H-308, Memphis, TN 38163. Telephone (901) $528-5730$.
B rief items of interest for the SHEA New $s$ or N ew sletter may be sent to Robert A. Weinstein, MD, SHEA, Newsletter Editor, Division of Infectious Diseases, Michael Reese Hospital, Lake Shore Drive at 31st St., Chicago, IL 60616; FAX (312) 791-3577. Copy must be typed, doublespaced, and may not exceed five pages. 